\title{
Calculating and Evaluating of the Achievements of Pharmaceutical Separation Engineering Course for Pharmaceutical Engineering Major Based on Engineering Education Certification
}

\author{
Hua $\mathrm{Li}^{\star}$, Xiaohua Shi \\ School of Chemical Engineering, Zhengzhou University, Zhengzhou, CHINA.
}

\begin{abstract}
Aim: This study aims to evaluate the efficiency of the achievement degree for engineering education certification, example as pharmaceutical separation engineering course. The calculating method of achievement degree about graduation requirement in engineering education certification in colleges and universities was introduced in this paper. Materials and Methods: A total 53 students were selected from the exam of pharmaceutical separation engineering course and the total score of the exam is 100 . Among them, objective total score: 70 , subjective total score: 30 . The calculation of course achievement degree is realized by Excel tool. Results: In order to make the evaluation process of achievement degree more reasonable, not only the graduation requirements and course achievement degree were calculated with Excel and statistical analysis and graphical analysis on the calculation results of course achievement degree were made, but also the achievement of course objectives and existing problems were analyzed and evaluated. For the students who need to pay attention to, it is necessary to analyze whether there are any problems that deviate from the focus and other problems in course learning, so as to help them overcome the problems in the follow-up study. Conclusion: This method is really student-centered and provides necessary information for teachers to revise and improve the teaching of courses at any time.
\end{abstract}

Key words: Professional certification, Graduation requirements, Achievement Degree, Excel.

\section{INTRODUCTION}

Engineering education professional certification has been started in China since 2006, which has been paid more and more attention by Colleges and Universities and specialties. Achievement-oriented education is the core of engineering education certification and curriculum achievement degree is the key to evaluation. Curriculum achievement degree refers to the ratio between knowledge and ability, process and method acquired by students through classroom learning and teaching objectives, which is a quantitative description of the implementation of teaching objectives. ${ }^{1-3}$ Through the quantitative analysis of achievement degree of each course, the current situation of the implementation of teaching objectives can be clearly shown and understood whether the indicators supporting graduation requirements of this course are balanced or not and then make continuous improvement to effectively implement the achievement efficiency of teaching objectives.

\section{Calculating Method of Course Achievement Degree}

Course Achievement Degree is calculated by tracking the whole learning process of the course and using quantitative data or recorded documents to prove whether the
Submission Date: 04-07-2019; Revision Date: 09-23-2019; Accepted Date: 11-16-2019

DOI: 10.5530/ijper.54.1.3 Correspondence: Prof. Hua Li,

School of Chemical Engineering, Zhengzhou University, Zhengzhou-450001, CHINA.

Phone: +86-371-67781801

E-mail: lihua@zzu.edu.cn

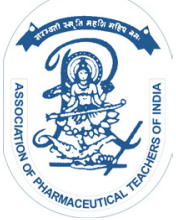

www.ijper.org 
students' ability has been achieved or not. Teachers in each academic year need to evaluate the curriculum achievement degree and statistics the curriculum assessment data, filling in the evaluation form of curriculum achievement degree.

According to the examination forms of courses, all or part of the test papers are sampled, counting the examination results of each assessment link of course on the indicators of the corresponding graduation requirements and determining the scoring rate of each examination form.

The curriculum objectives are achieved by the teachers who are in charge of evaluating the curriculum objectives and assessment methods of the syllabus every school year. In the syllabus, the support relationship between the curriculum objectives and the indicators of graduation requirements should be clarified and the specific assessment links should be set for the curriculum objectives. ${ }^{4-6}$ Taking the course of Pharmaceutical Separation Engineering as an example, the curriculum objectives are as follows:

Through the study of this course, students can achieve the following abilities:

Firstly, students can use the basic theory, principle and process of the main separation technologies involved in pharmaceutical processes and to propose possible solutions or design objectives by requirements of the proposed solutions

Secondly, Students can select or design reasonable process routes and make preliminary process estimation according to the characteristics of the separated objects and understand the main factors affecting them, so as to provide a basis for the correct selection of equipment or devices.
Thirdly, in the development, process design and optimization of pharmaceutical separation technology, students can comprehensively consider such factors as technological economy, project management and technological maturity, analyzing and comparing the basic characteristics of major separation technologies and equipment and understanding its development trend.

\section{Calculation and Evaluation of Course Achievement Degree}

The number of students taking the exam is 53 and the total score of the paper is 100 . Among them, objective total score: 70 , subjective total score: 30 . The calculation of course achievement degree is realized by Excel. See Appendix: EXCEL calculates the original data. Statistical analysis of data is listed in Table 1.

\section{Statistical Analysis}

\section{Graph Analysis}

Overall achievement degree of each course objective is shown in Figure 1. Distribution of achievement degree is shown in Figure 2.

\section{Analysis on Achieving the Whole Course Goals of Teaching Class}

Analysis of Achievement of Course Goals and Existing Problems

\section{Analysis of Overall Achievement}

The high score (above 90 ) accounted for $7.55 \%$, which is slightly lower than that in previous years. No students failed and the distribution of achievement degree is concentrated around the range of $80 \%$ to $89 \%$, which is improved compared with previous years, reflecting

\begin{tabular}{|c|c|c|c|c|}
\hline \multicolumn{2}{|c|}{ Table 1: Statistical Analysis of Specific Data. } \\
\hline Course Achievement Degree & Goal 1 & Goal 2 & Goal 3 & Average value(\%) \\
\hline Average Value & $76.33 \%$ & $91.51 \%$ & $71.32 \%$ & $79.72 \%$ \\
\hline Median & $77.14 \%$ & $100 \%$ & $80 \%$ & $85.71 \%$ \\
\hline Standard Deviation & $8.63 \%$ & $13.93 \%$ & $26.57 \%$ & $16.38 \%$ \\
\hline Maximum Achievement & $91.43 \%$ & $100 \%$ & $100 \%$ & $97.14 \%$ \\
\hline Minimum Achievement & $55.71 \%$ & $40 \%$ & 0 & $31.90 \%$ \\
\hline Achievement Distribution & Proportion (\%) & Proportion (\%) & Proportion (\%) & $\begin{array}{c}\text { Total Achievement } \\
\text { Distribution }\end{array}$ \\
\hline $\mathbf{2 9 0} \%$ & $5.66 \%$ & $75.47 \%$ & $30.19 \%$ & $7.55 \%$ \\
\hline $\mathbf{8 0 \% ~ 8 9 \%}$ & $32.08 \%$ & $13.21 \%$ & $37.74 \%$ & $43.40 \%$ \\
\hline $\mathbf{7 0 \% ~ 7 9 \%}$ & $41.51 \%$ & $3.77 \%$ & $5.66 \%$ & $33.96 \%$ \\
\hline $\mathbf{6 0 \% \sim 6 9 \%}$ & $18.87 \%$ & $3.77 \%$ & $3.77 \%$ & $15.09 \%$ \\
\hline$\leq 60 \%$ & $1.89 \%$ & $3.77 \%$ & $22.64 \%$ & 0 \\
\hline Methods & Final Examination & Final Examination & Final Examination & Average Course \\
\hline & & & Achievement $78.87 \%$ \\
\hline
\end{tabular}




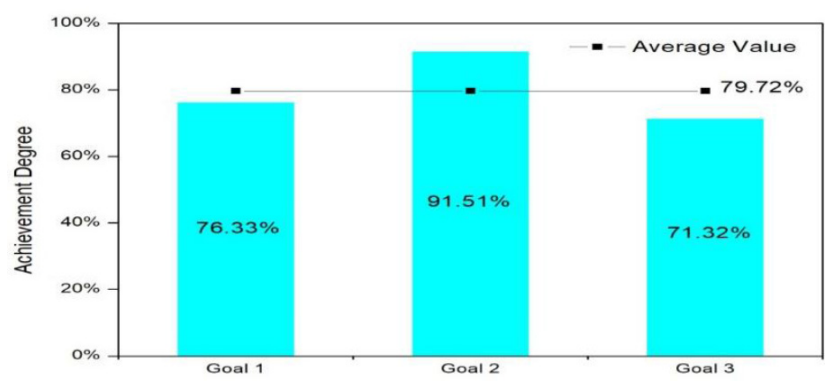

Figure 1: Overall achievement degree of each course objective.
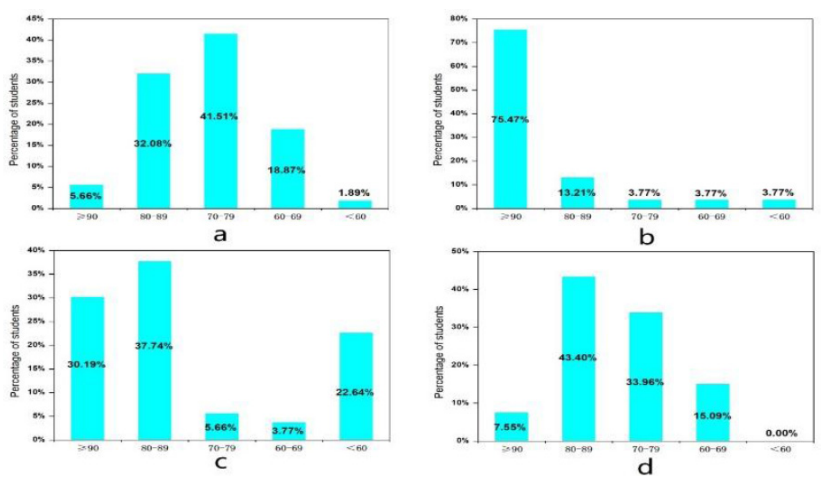

Figure 2: Distribution of Achievement Degree: (a) Distribution of Achievement Degree of Curriculum Goal 1; (b) Distribution of Achievement Degree of Curriculum Goal 2; (c) Distribution of Achievement Degree of Curriculum Goal 3; (d) Distribution of the Overall Achievement Degree of Courses.

that most students could master the basic knowledge of this course. Meanwhile, it also indicates that the overall depth, breadth and amount of questions are basically appropriate and the difficulty is moderate, so that the desired teaching goal could be achieved.

\section{Analysis of Achievement of Course Goal 1}

Course Objective 1 is to cultivate students' ability to apply basic concepts, theories and processes of pharmaceutical separation engineering to basic engineering and professional knowledge. Correctness of this part is generally high, with an average of $76.33 \%$, a maximum of $91.43 \%$ and a minimum of $55.71 \%$. The overall situation of the students is very good. They have a relatively solid grasp of knowledge and can apply what they have learned, which is reflected in their daily classroom performance and homework.

\section{Analysis of Achievement of Course Goal 2}

Course objective 2 is to train students to select or design reasonable process routes and make preliminary process estimation according to the characteristics of the separated objects and to understand the main factors affecting the process, so as to provide a basis for the correct selection of equipment or devices. This part needs a certain sum-up and generalization ability. Average achievement degree of this part is $91.51 \%$, the highest degree is $100 \%$ and the lowest degree is $40 \%$. Most of the students can give a reasonable plan according to their knowledge and ideas they have learned, but the main problem is that the answers are not comprehensive enough. In addition, some students' answers are too lengthy and lack of generality, which shows that the students do not understand the key points of the course thoroughly enough.

\section{Analysis of Achievement of Course Goal 3}

Course objective 3 is to analyze and compare the basic characteristics of main separation technologies and equipment and understand their development trends in pharmaceutical separation technology development, process design and optimization, taking into account such factors as technological economy, project management and technological maturity. This part is difficult for students who lack practical experience. The average achievement degree is $71.32 \%$, the highest achievement degree is $100 \%$ and the lowest achievement degree is $0 \%$. Compared with the previous two items, the average and minimum achievement degree are the lowest. Students have different levels of mastery. Their understanding, analysis and solving abilities of complex process need to be further improved. What they have learned needs to be summarized and put into practice.

In a word, the answers of the examination paper are better and there is not a big gap between the students' scores. Students can understand the key points of textbook knowledge to a certain extent and solve problems after thinking independently. Only a few students do not pay enough attention to the examination. In the future teaching, we should pay more attention to individual students and improve their interest in learning.

\section{Reflections on Further Improvement of Teaching in the Future}

This course is one of the professional core courses of pharmaceutical engineering major and it is a course that students must understand and master. This exam, the overall performance of the whole grade students is good and there are few students with poor performance. Most students achieve good results, which may be because more students try their best to understand this course. After class, they discuss the problems with other students, combined with the ideas of other students to make their own thinking more comprehensive. For the future teaching, more classroom discussions will be conducted to improve students' understanding and analysis of complex process problems and more examples will be used to improve students' interest as well as their ability to solve problems. 


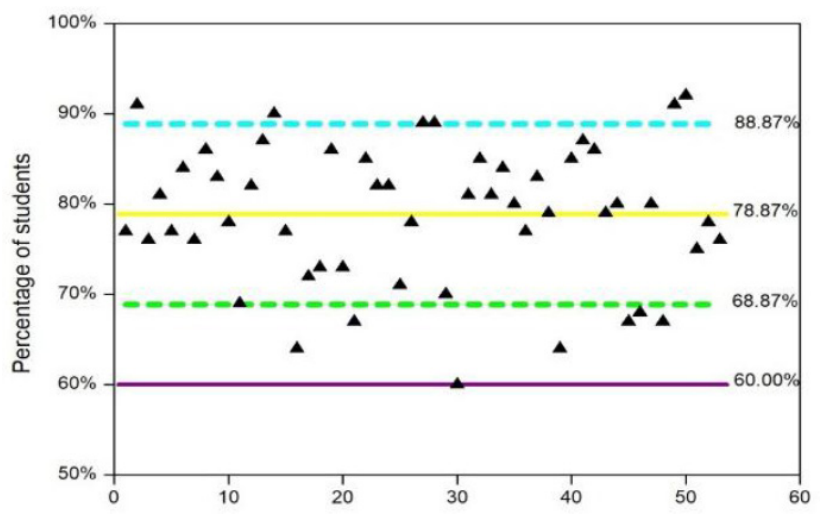

Figure 3: Distribution Graph of Achievement Degree of Students' Courses.

Table 2: Students who need attention and follow-up.

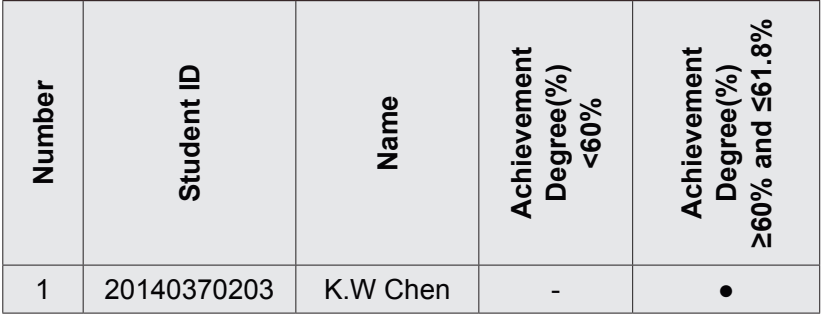

\section{Analysis on Achieving the Course Objectives of} each Student

\section{Distribution Map of Students' Course Achievement}

Distribution graph of achievement degree of students' courses is shown in Figure 3.

It can be seen from all the students' achievement degree that the average achievement degree is $78.87 \%$ and no students are less than $60 \%$. Most of the students' scores are distributed in the range of $10 \%$ above and below the median achievement degree, which shows that the overall mastery of the students in this course is better and meets the teaching requirements. However, there are still some students with low achievement degree, which needs to be focused on.

\section{Students who need attention and follow-up}

The result of students who need attention and followup is listed in Table 2.

Only one student's achievement degree is between $60 \%$ and $61.8 \%$. It is necessary to focus on the student's learning attitude and understand its difficulties in the learning process, providing targeted assistance in the later teaching. Seven students' achievement degree is less than $10 \%$ of the average achievement degree. We need to analyze whether there are any problems that deviate from the focus and other problems in learning the course. If necessary, we should communicate with the students in order to help them overcome relative problems in the follow-up study.

\section{CONCLUSION}

Accurate and fast calculation of achievement degree and achievement of course objectives can help teachers to collect the data of students' learning situation and reaction to the curriculum, so as to measure the degree of achievement of curriculum goals in time and find out what needs to be improved in curriculum teaching. It also provides necessary information for revising and improving teaching at any time, so as to truly realize the student-centered teaching.

\section{ACKNOWLEDGEMENT}

This work was supported by Research funding from the reform in education project in Zhengzhou University and Postgraduate Education Reform and Quality Improvement Project of Henan Province, No. HNYJS2020KC03.

\section{CONFLICT OF INTEREST}

The authors declare no conflict of interest.

\section{REFERENCES}

1. Bao B, Wu WH, Zhang CY, Wang CX. Establishment of an Evaluation System for Achieving Basic Teaching Objectives: A Case Study of "Professional English". University Education. 2014;3:53-5.

2. Wang SY, Dong W, Zheng JS, Liu L. Research and Practice of Graduates' Graduation Requirement Achievement Evaluation Method Based on Engineering Education Professional Certification Standard. Industry and Information Education. 2016;4:15-22.

3. Zhang WY, Gao F, Yang J. Development of Graded Employment Information Management System for College-level Post under Excel Environment. China Education Info. 2014;16:46-8.

4. Allred ZDR, Bretz SL. University chemistry students' interpretations of multiple representations of the helium atom. Chem Educ Res Pract. 2019;20(2):358-68.

5. $\mathrm{Li} \mathrm{H}, \mathrm{Hu} \mathrm{GQ}$, Hou CH. Innovation of new Engineering Teaching Model of World-Class Universities. International Education and Research Journal. 2019;5(6):58-9.

6. Li H, Wang XM, Hu GQ. Research on Grading Method of Courses Based on Engineering Professional Certification. International Education and Research Journal. 2018;4(11):8-10. 


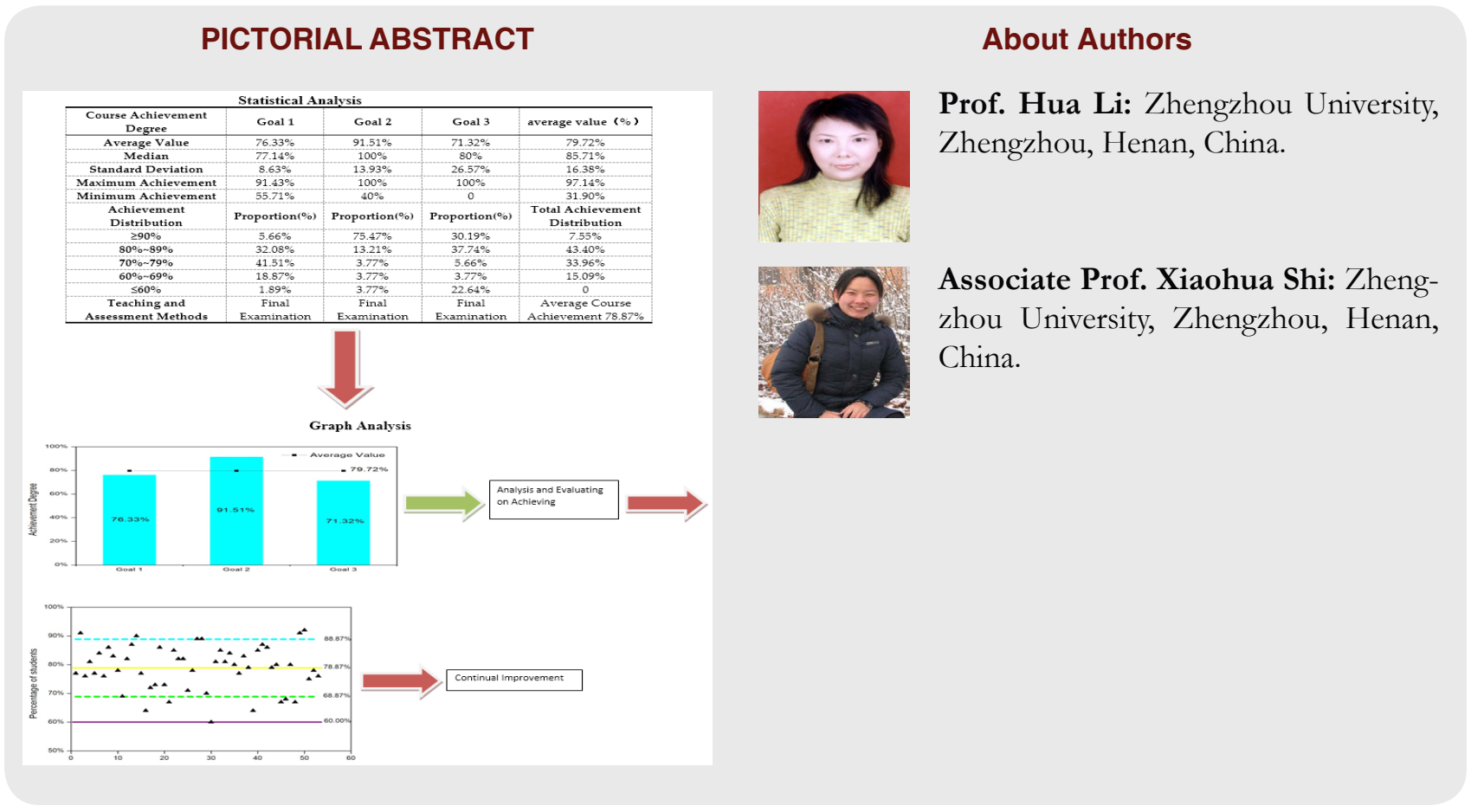

Cite this article: Li H, Shi X. Calculating and Evaluating of the Achievements of Pharmaceutical Separation Engineering Course for Pharmaceutical Engineering Major Based on Engineering Education Certification. Indian $\mathrm{J}$ of Pharmaceutical Education and Research. 2020;54(1):17-21. 